\title{
Knowledge and attitudes about human papillomavirus, Pap smears, and cervical cancer among young women in Brazil: implications for health education and prevention
}

\author{
E.D. MOREIRA JR*†, B.G. OLIVEIRA*†, F.M. FERRAZ*†, S. COSTA \\ J.O. COSTA FILHO $\neq$ \& G. KARIC $\neq$ \\ *Núcleo de Apoio à Pesquisa, Fundação Irmã Dulce, Salvador, Bahia, Brazil; †Centro de Pesquisas Gonçalo \\ Moniz, Fundação Oswaldo Cruz, Salvador, Bahia, Brazil; and ‡Laboratórios Merck, Sharp \& Dohme, \\ São Paulo, Brazil
}

\begin{abstract}
Moreira ED Jr, Oliveira BG, Ferraz FM, Costa S, Costa Filho JO, Karic G. Knowledge and attitudes about human papillomavirus, Pap smears, and cervical cancer among young women in Brazil: implications for health education and prevention. Int J Gynecol Cancer 2006;16:599-603.
\end{abstract}

The objective of the study was to assess knowledge and attitudes about human papillomavirus (HPV), cervical cancer, and Papanicolaou (Pap) smears among young women. A questionnaire was administered to 204 women aged 16-23 years, attending a public clinic. Data were gathered on sociodemographic characteristics, knowledge, and attitudes related to HPV. Overall, 92\% of women reported current/previous sexual activity, $42 \%$ perceived themselves at high risk of acquiring a sexually transmitted disease, $67 \%$ did not know that HPV can cause cervical cancer/warts, and only $10 \%$ acknowledged that HPV might lead to cervical cancer. In general, women had a poor knowledge on HPV diagnosis/treatment, condyloma signs, and Pap smear test. The main reasons for not having a Pap smear test done before were embarrassment $(63 \%)$ and fear of pain $(61 \%)$. Knowledge of HPV infection and cervical cancer was low in this urban young population. Our findings recommend for greater HPV education of the public and health care practitioners.

KEYWORDS: cervical cancer, genital warts, human papillomavirus, knowledge, Pap smear screening, young women.

Human papillomavirus (HPV) is one of the most prevalent sexually transmitted viral diseases ${ }^{(1-4)}$. Several types of HPV infect the anogenital area and are spread through skin-to-skin contact that occurs during sex ${ }^{(5)}$. Types 16 and 18 are associated with $70 \%$ of the cervical dysplasia and cervical cancer cases ${ }^{(6-10)}$, whereas types 6 and 11 cause virtually all genital warts in both women and men ${ }^{(4,11)}$. Cervical cancer is second worldwide among malignancies for causing death among women ${ }^{(12,13)}$. While cervical cancer mortality has declined due to early detection by Papanicolaou (Pap) smears, treatment of precancerous lesions caused by HPV still causes considerable physical and psychologic morbidity as well as considerable expense ${ }^{(14,15)}$.

Address correspondence and reprint requests to: Edson Duarte Moreira Jr, MD, PhD, Rua Waldemar Falcão 121, Salvador, Bahia, Brazil CEP 40.295-001. Email: edson@cpqgm.fiocruz.br
Despite the high prevalence and serious complications associated with HPV infection, most young women know very little about $\mathrm{HPV}^{(16-19)}$. Relatively few studies have examined knowledge of HPV. Almost all are US-based surveys and most sample only US college women ${ }^{(1,18,20-23)}$. In the United States, Koutsky et al ${ }^{(1)}$ found that $11-46 \%$ of college women were infected with HPV. In another study by Hoover et al., only $8 \%$ of the women between 15 and 17 years of age and $35 \%$ of those from 18 to 28 years of age knew about HPV ${ }^{(18)}$. Public awareness of HPV and its association with cervical cancer may motivate women to participate in HPV primary prevention efforts, as well as to engage in other risk-reduction programs such as routine Pap smear screening. Awareness and education are important prerequisites to efforts aimed at preventing the spread of HPV. The purpose of this study was to assess knowledge, beliefs, and attitudes 
about HPV infection, cervical cancer, and Pap smears among young women in an urban center in northeastern Brazil.

\section{Materials and methods}

\section{Study population and site}

We recruited a consecutive sample of women of age 16-23 years at the waiting room of the gynecological clinic at the Santo Antônio Hospital in Salvador city, in northeastern Brazil. This free, nongovernmental clinic delivers health care to uninsured women of lower socioeconomic status. Out of 237 eligible women, 33 refused to participate and 204 (86.1\% response rate) were surveyed from May to July 2002. Respondents were approached by interviewers and invited to participate in the survey. The protocol was approved by the Hospital Ethical Committee. Informed consent was obtained from all participants.

\section{Data collection}

There were three study interviewers (two males and one female), who were given an orientation on the protocol and specific details concerning participation in the study. Prior to study commencement, they carried out practice sessions with authentic respondents. These preliminary interviews were observed and critiqued by the investigators. The interview guides were developed from a review of the literature and contained sections of questions that addressed the major areas to be explored by the study: knowledge of HPV, genital warts, cervical cancer, and Pap smear screening ${ }^{(24-26)}$.

The 150-item questionnaire was divided into five sections that sought information about the following: (1) demographic data and social background; (2) use of the clinic; (3) awareness and understanding of HPV, genital warts, and cervical cancer, including signs and symptoms, routes of transmission, prevention, potential long-term complications, diagnosis, and treatment; (4) knowledge and understanding of Pap smear screening; and (5) sexual behavior and self-perceived risk of acquiring a sexually transmitted disease (STD). The questionnaire was piloted on a sample of 20 female volunteer patients attending the clinic. All items were assessed for face validity by health survey experts. The individual interviews lasted an average 20-25 min, and the sessions occurred in a private room.

\section{Data analysis}

The data were analyzed using the Statistical Package for the Social Sciences. Basic descriptive statistics and frequency calculations were performed on all variables, $\chi^{2}$ test was used to assess differences in answers by categories of stratifying variables, with statistical significance at $5 \%$.

\section{Results}

The mean age (standard deviation) of women in our sample was 20.0 (2.0) years; $74.0 \%$ were single, $25.5 \%$ were married or living with a partner, $21.1 \%$ were currently employed, and $61.3 \%$ had a high school education or more. They were ethnically diverse: $2.0 \%$ white, $25.5 \%$ black, and $72.5 \%$ of mixed ethnicity. More than half of the participants were catholic (54.4\%), and $40 \%$ were full-time students. Selected information on the study participants are depicted in Table 1. Ninety-two percent of women reported current or previous sexual activity and were classified as sexually experienced. Forty-two percent of the respondents perceived themselves at a high risk of acquiring an STD, notwithstanding 55\% never or rarely used condom. The majority of women were first-time users of the clinic and had come for a Pap smear test.

Table 2 summarizes subjects' responses to questions about HPV, condyloma, and cervical cancer. More than two thirds of the respondents (68.6\%) ignored

Table 1. Selected characteristics of 204 women in Salvador, Brazil, 2002

\begin{tabular}{|c|c|}
\hline & $N(\%)$ \\
\hline \multicolumn{2}{|l|}{ Sexual behavior } \\
\hline \multicolumn{2}{|l|}{ Number of lifetime sexual partners } \\
\hline None & $16(7.8)$ \\
\hline One partner & $78(38.2)$ \\
\hline Two partners & $44(21.6)$ \\
\hline Three partners & $30(14.7)$ \\
\hline Four partners & $18(8.8)$ \\
\hline$\geq$ Five partners & $18(8.8)$ \\
\hline \multicolumn{2}{|l|}{ How often do you use condom $?^{a}$} \\
\hline Never & $45(23.9)$ \\
\hline Rarely & $58(30.9)$ \\
\hline Often & $34(18.1)$ \\
\hline Always & $51(27.1)$ \\
\hline \multicolumn{2}{|l|}{ Self-perceived risk of acquiring an $\mathrm{STD}^{a}$} \\
\hline None & $34(18.1)$ \\
\hline Low & $68(36.2)$ \\
\hline Moderate & $7(3.7)$ \\
\hline High & $79(42.0)$ \\
\hline \multicolumn{2}{|l|}{ Use of clinic } \\
\hline First time at the clinic & $121(59.3)$ \\
\hline \multicolumn{2}{|l|}{ Main reason for the consultation } \\
\hline Pap smear screening test & $103(50.5)$ \\
\hline Birth control & $30(14.7)$ \\
\hline Other gynecological consultation & $71(34.8)$ \\
\hline
\end{tabular}

${ }^{a}$ Only for sexually active women $(n=188)$. 
Table 2. Knowledge and awareness about HPV, genital warts, and cervical cancer among 204 women in Salvador, Brazil, 2002

\begin{tabular}{|c|c|}
\hline & $\%$ \\
\hline \multicolumn{2}{|l|}{ HPV } \\
\hline \multicolumn{2}{|l|}{ What HPV causes? } \\
\hline Do not know & 68.6 \\
\hline Cervical cancer & 9.8 \\
\hline Genital warts & 4.9 \\
\hline Other & 16.7 \\
\hline \multicolumn{2}{|l|}{ How HPV is contracted? } \\
\hline Sexual contact & 66.7 \\
\hline Do not know & 24.5 \\
\hline Sharing underwear or towels & 3.9 \\
\hline Toilet seats & 2.0 \\
\hline Other & 2.9 \\
\hline \multicolumn{2}{|l|}{ Condyloma } \\
\hline \multicolumn{2}{|l|}{ What is the main sign of condyloma? } \\
\hline Do not know & 56.0 \\
\hline Genital warts & 17.6 \\
\hline Genital ulcers & 7.8 \\
\hline Vaginal discharge & 4.9 \\
\hline Genital blisters & 2.9 \\
\hline Other & 10.8 \\
\hline \multicolumn{2}{|l|}{ How condyloma is contracted? } \\
\hline Sexual contact & 57.4 \\
\hline Do not know & 39.6 \\
\hline Casual contact & 1.5 \\
\hline Other & 1.5 \\
\hline \multicolumn{2}{|l|}{ Cervical cancer } \\
\hline \multicolumn{2}{|l|}{ What may lead to cervical cancer? } \\
\hline Do not know & 60.8 \\
\hline Fail to undergo Pap screening test & 10.8 \\
\hline STDs & 3.9 \\
\hline Other & 24.5 \\
\hline \multicolumn{2}{|l|}{ Are you concerned about } \\
\hline \multicolumn{2}{|l|}{ having/developing cervical cancer? } \\
\hline No & 6.8 \\
\hline A little & 20.6 \\
\hline Moderately & 42.2 \\
\hline Extremely & 30.4 \\
\hline \multicolumn{2}{|c|}{ Self-perceived chance of developing cervical cancer } \\
\hline Very low & 16.7 \\
\hline Low & 15.2 \\
\hline Average & 56.8 \\
\hline High & 11.3 \\
\hline
\end{tabular}

what HPV may cause. Overall, less than $10 \%$ of the women acknowledged that HPV might lead to cervical cancer. In contrast, most women knew that HPV is sexually transmitted (66.7\%). Study participants with some high school education were more likely to know about the association between HPV and cervical cancer than those with less than high school education, $17.0 \%$ and $6.1 \%$, respectively $\left(\chi^{2}=4.26, P=0.04\right)$. Subjects with higher educational attainment were also more likely to have knowledge on HPV transmission as compared to those less educated, $72.8 \%$ and $56.9 \%$, respectively $\left(\chi^{2}=5.46, P=0.02\right)$. In general, women in our study demonstrated a poor knowledge on how HPV is diagnosed or treated (Table 2). More than half of the women were not aware of the presenting signs of condyloma, and only $17.6 \%$ acknowledged genital warts as a sign of this condition. Knowledge of cervical cancer was also poor. The majority of women $(60.8 \%)$ did not realize what might lead to cervical cancer, and only $3.9 \%$ reported STDs, nonspecifically, as a possible reason for this cancer (Table 2). Risk factors, as noted by the respondents, included not having regular smear tests, lack of personal hygiene, and others. Of note, $72.6 \%$ of the participants were moderately to extremely concerned about cervical cancer, and $68.1 \%$ perceived themselves at moderate to high risk of developing this type of cancer.

As shown in Table 3, knowledge about Pap smear test among subjects in our survey was low. The majority of women in our study (78\%) had limited knowledge about the purpose of this screening test. They either reported that it serves to prevent "diseases," nonspecifically, or were not sure why they should have a smear test done. Approximately 19\% of the women had not undergone a Pap smear test before. The most common reason reported for not having a screening test performed was embarrassment (63.2\%), followed closely by fear of pain $(60.5 \%)$. The obstacles to undergo a Pap test were similarly prevalent among

Table 3. Knowledge and attitudes about Pap smear screening among 204 women in Salvador, Brazil, 2002

\begin{tabular}{|c|c|}
\hline & $N(\%)$ \\
\hline \multicolumn{2}{|c|}{ What is the Pap smear screening test used for? } \\
\hline To prevent diseases (nonspecifically) & $154(75.5)$ \\
\hline To prevent STDs & $23(11.3)$ \\
\hline To prevent cervical cancer & $15(7.4)$ \\
\hline To prevent cervical cancer and STDs & $6(2.8)$ \\
\hline Do not know & $5(2.5)$ \\
\hline Other & $1(0.5)$ \\
\hline \multicolumn{2}{|c|}{ Have you already undergone a Pap smear test? } \\
\hline No & $38(18.6)$ \\
\hline \multicolumn{2}{|l|}{ Why not? } \\
\hline Embarrassment & $24(63.2)$ \\
\hline Fear of pain & $23(60.5)$ \\
\hline Cannot get an appointment & $13(34.2)$ \\
\hline Do not bother & $12(31.6)$ \\
\hline Other & $4(10.6)$ \\
\hline Yes & $166(81.4)$ \\
\hline \multicolumn{2}{|l|}{$\begin{array}{l}\text { Do you feel embarrassed when } \\
\text { undergoing a Pap smear test? }\end{array}$} \\
\hline Yes & $96(57.8)$ \\
\hline No & $70(42.2)$ \\
\hline \multicolumn{2}{|l|}{ Do you feel pain when undergoing } \\
\hline \multicolumn{2}{|l|}{ Pap smear test? } \\
\hline Yes & $79(47.6)$ \\
\hline No & $87(52.4)$ \\
\hline
\end{tabular}

(C) 2006 IGCS, International Journal of Gynecological Cancer 16, 599-603 
participants, despite their education. Among women who had already had a Pap test before, nearly half (48\%) did report pain during the gynecological examination and $58 \%$ felt embarrassed while having the test done.

\section{Discussion}

This is the first comprehensive survey on knowledge and attitudes about HPV infection and cervical cancer among young women in northeastern Brazil. Our results show that little is known about these health topics in the study population. Overall, more than two thirds of the women in our sample did not know the potential consequences of HPV and less than 10\% knew that it might lead to cervical cancer. Similar findings have been reported among women attending college in the United States ${ }^{(20-22)}$ and among female employees at a university in the $\mathrm{UK}^{(19)}$, where more than half of the respondents had low level of knowledge about genital HPV infections, thus indicating that HPV-related knowledge deficits also occur among subjects with higher educational attainment and suggesting that HPV educational programs may be needed in both developing and developed countries.

Knowledge of HPV transmission, presenting symptoms and signs, and HPV association with greater risk of cervical cancer were associated with years of school attendance. Women with higher educational attainment were more likely to have received information on these matters. However, the lack of knowledge on HPV diagnosis and treatment was prevalent in women, regardless of their education, suggesting that the amount of information they may receive at high school is still insufficient or limited. A high proportion of the women in our study (73\%) reported that they were moderately/extremely worried about having/developing cervical cancer. Moreover, the majority of the respondents $(68 \%)$ believed that they were at moderate to high risk for cervical cancer. In this scenario, where poor HPV-related knowledge coexists with high perceived susceptibility to cervical cancer, one may argue that HPV educational programs are not only needed but also likely to be welcomed.

Many women in our survey (81\%) had already undergone a Pap smear screening. This may derive from the sampling strategy we used (based on a clinical setting) and may not reflect what probably happens in the general population. Despite that, most women in our study only knew that the Pap test was meant to prevent diseases nonspecifically, denoting an incomplete/partial knowledge of the rationale for this exam. It is conceivable that if women were given more information about the purposes of the Pap screening test (prevention and early diagnosis/treatment of cervical cancer, the second most common cancer in women), this could improve their adherence to future visits in such programs. In fact, a study by Fernandez et $a .^{(27)}$ has demonstrated that a health promotion program that provided education for medically underserved women was successful in increasing mammography and Pap test screening among low-income and minority women.

The main reasons women reported for not having undergone a smear test before were embarrassment and fear of pain. In fact, $76 \%$ of the respondents cited either one as an obstacle to undergo a first smear test. Interestingly, among women who had already undergone a Pap smear test, a significant proportion still reported embarrassment (58\%) and nearly half of them $(48 \%)$ indeed felt pain during the gynecological exam for the Pap test. These issues should be targeted in programs to increase compliance to future cervical screening among women in this population.

Our study supports the National Institutes of Health Consensus Conference recommendations highlighting the need for greater HPV education of the public and health care providers ${ }^{(28)}$. Encouragingly, women's concerns about cervical cancer and interest in learning more about HPV were high among respondents in our survey. Designing and implementing HPV educational programs and measuring their effectiveness should be priorities. In addition, the main obstacles to a first Pap test women reported in our study (embarrassment and fear of pain) are both potentially modifiable through education of patients and practitioners and should be addressed in campaigns to incentive women to join and comply with Pap screening programs.

\section{Acknowledgments}

The authors would like to thank Mrs. Silvana Fonseca for her assistance in conducting the interviews; and Gregory Zimet, $\mathrm{PhD}$, for sharing his questionnaire of a previous survey on HPV knowledge.

\section{References}

1 Koutsky L. Epidemiology of genital human papillomavirus infection. Am J Med 1997;102:3-8.

2 Moscicki AB. Human papillomavirus infection in adolescents. Pediatr Clin North Am 1999;46:783-807.

3 Dillner J, Meijer CJ, von Krogh G, Horenblas S. Epidemiology of human papillomavirus infection. Scand J Urol Nephrol Suppl 2000; 205:194-200

4 Franceschi S, Castellsague X, Dal Maso L et al. Prevalence and determinants of human papillomavirus genital infection in men. $\mathrm{Br} J$ Cancer 2002;86:705-11. 
5 zur Hausen H. Human papillomaviruses in the pathogenesis of anogenital cancer. Virology 1991;184:9-13.

6 Daley EM. Clinical update on the role of HPV and cervical cancer Cancer Nurs 1998:21:31-5.

7 Bosch FX, Manos MM, Munoz N et al. Prevalence of human papillomavirus in cervical cancer: a worldwide perspective. International biological study on cervical cancer (IBSCC) Study Group. J Natl Cancer Inst 1995;87:796-802.

8 Herrington CS. Human papillomaviruses and cervical neoplasia. I. Classification, virology, pathology, and epidemiology. J Clin Pathol 1994;47:1066-72.

9 Reeves WC, Brinton LA, Garcia M et al. Human papillomavirus infection and cervical cancer in Latin America. N Engl J Med 1989; 320:1437-41.

10 Ho GY, Bierman R, Beardsley L, Chang CJ, Burk RD. Natural history of cervicovaginal papillomavirus infection in young women. N Engl J Med 1998;338:423-8.

11 Stone KM. Human papillomavirus infection and genital warts: update on epidemiology and treatment. Clin Infect Dis 1995; 20(Suppl. 1):S91-7.

12 Landis SH, Murray T, Bolden S, Wingo PA. Cancer statistics, 1999. CA Cancer J Clin 1999:49:8-31.

13 Black RJ, Bray F, Ferlay J, Parkin DM. Cancer incidence and mortality in the European Union: cancer registry data and estimates of national incidence for 1990. Eur J Cancer 1997;33:1075-107.

14 Helms LJ, Melnikow J. Determining costs of health care services for cost-effectiveness analyses: the case of cervical cancer prevention and treatment. Med Care 1999;37:652-61.

15 Barton DP, Butler-Manuel S, Buttery LD, A'Hern R, Polak JM. Radical hysterectomy for early stage cervical cancer and resulting morbidity. Gynecol Oncol 2001;82:410-1.

16 Mays RM, Zimet GD, Winston Y, Kee R, Dickes J, Su L. Human papillomavirus, genital warts, Pap smears, and cervical cancer: knowledge and beliefs of adolescent and adult women. Health Care Women Int 2000;21:361-74.
17 Dell DL, Chen H, Ahmad F, Stewart DE. Knowledge about human papillomavirus among adolescents. Obstet Gynecol 2000;96:653-6.

18 Hoover DR, Carfioli B, Moench EA. Attitudes of adolescent/young adult women toward human papillomavirus vaccination and clinical trials. Health Care Women Int 2000;21:375-91.

19 Pitts M, Clarke T. Human papillomavirus infections and risks of cervical cancer: what do women know? Health Educ Res 2002;17:706-14.

20 Lambert EC. College students' knowledge of human papillomavirus and effectiveness of a brief educational intervention. J Am Board Fam Pract 2001;14:178-83.

21 Yacobi E, Tennant C, Ferrante J, Pal N, Roetzheim R. University students' knowledge and awareness of HPV. Prev Med 1999;28:535-41.

22 Ramirez JE, Ramos DM, Clayton L, Kanowitz S, Moscicki AB. Genital human papillomavirus infections: knowledge, perception of risk, and actual risk in a nonclinic population of young women. $J$ Womens Health 1997;6:113-21.

23 Linnehan MJ, Andrews S, Groce NE. College health providers' knowledge, attitudes, and management practices of genital HPV infection. Nurse Pract 1996;21:122-4, 127-9.

24 Vail-Smith K, White DM. Risk level, knowledge, and preventive behavior for human papillomaviruses among sexually active college women. J Am Coll Health 1992;40:227-30.

25 Zimet GD, Fortenberry JD, Fife KH, Tyring SK, Herne K, Douglas JM. Acceptability of genital herpes immunization. The role of health beliefs and health behaviors. Sex Transm Dis 1997;24:555-60.

26 Liau A, Zimet GD, Fortenberry JD. Attitudes about human immunodeficiency virus immunization: the influence of health beliefs and vaccine characteristics. Sex Transm Dis 1998;25:76-81.

27 Fernandez ME, DeBor M, Candreia MJ, Wagner AK, Stewart KR Evaluation of ENCOREplus. A community-based breast and cervical cancer screening program. Am J Prev Med 1999;16(Suppl. 3):35-49.

$28 \mathrm{NIH}$ releases consensus statement on cervical cancer. Am Fam Physician 1996;54:2310, 2315-6.

Accepted for publication December 1, 2004 